\title{
ULTRA SMALL-MASS GRAPHITIZATION BY SEALED TUBE ZINC REDUCTION METHOD FOR AMS ${ }^{14} \mathrm{C}$ MEASUREMENTS
}

\begin{abstract}
Xiaomei $\mathrm{Xu}^{1,2} \cdot{\text { Pan } \mathrm{Gao}^{1,3} \cdot \text { Eric G Salamanca }}^{1}$
ABSTRACT. A modified sealed tube Zn reduction method based on Khosh et al. (2010) has been developed to graphitize ultra small-mass samples ranging from 4-15 $\mu \mathrm{g}$ carbon (C) for accelerator mass spectrometry (AMS) radiocarbon measurements. In this method, the reagent $\mathrm{TiH}_{2}$ is removed from the previous method while the amounts of $\mathrm{Zn}$ and Fe powder remain the same. The volume of the sealed reactor is further reduced by $\sim 40 \%$ to $\sim 0.75 \mathrm{~cm}^{3}$ and the graphitization temperature is lowered to $450{ }^{\circ} \mathrm{C}$. Graphite targets produced by this method generally yield ${ }^{12} \mathrm{C}^{+1}$ currents of about $0.5 \mu \mathrm{A}$ per $1 \mu \mathrm{g} \mathrm{C}$, similar to the small mass $(15-100 \mu \mathrm{g} \mathrm{C})$ sealed tube $Z n$ reduction method previously reported by Khosh et al. (2010) when measured on the same AMS system at KCCAMS, University of California, Irvine. Change of Fe powder to Sigma-Aldrich (400-mesh) has yielded further improved backgrounds over Fe powder of Alfa Aesar (325-mesh). Modern C background from combustion and graphitization is estimated to be $0.2-0.8 \mu \mathrm{g} \mathrm{C}$, and dead-C background to be $0.1-0.4 \mu \mathrm{g}$ C. The accuracy and precision of ultra small-mass samples prepared by this method are size and ${ }^{14} \mathrm{C}$ content dependent, but is usually $\pm 4-5 \%$ for the smallest sample size of $\sim 4-5 \mu \mathrm{g}$ C with modern ${ }^{14} \mathrm{C}$ content. AMS on-line $\delta^{13} \mathrm{C}$ measurement that allows for correction of both graphitization and machine-induced isotopic fractionation is the key for applying the sealed tube $\mathrm{Zn}$ reduction method to ultra small-mass sample graphitization.
\end{abstract}

\section{INTRODUCTION}

Ultra small-mass $(<25 \mu \mathrm{g} \mathrm{C})$ radiocarbon analysis by accelerator mass spectrometry (AMS) has gained higher demand in recent years because of the increasing needs of compound specific radiocarbon dating (CSRD), and for biological dating of specific cells in specific organs, such as in brains, hearts, etc. The amount of materials from these samples is usually in the $\mu \mathrm{g} \mathrm{C}$ range, often $<25 \mu \mathrm{g} \mathrm{C}$ after multiple chemical extraction steps that often involve chromatographic separations. Although ultra-small $\mathrm{CO}_{2}$ gas samples can be successfully measured by $\mathrm{CO}_{2}$ gas ion source AMS, such as the work by Fahrni et al. (2010), graphitization of ultra small-mass samples still poses some advantages because solid graphite targets can usually last longer in a solid ion source. Longer measurement time would allow lower statistical counting error and thus result in higher measurement precision, as long as the backgrounds associated with graphitization can be controlled and quantified. Several methods using $\mathrm{H}_{2}$ reduction have shown to be able to successfully graphitize ultra small-mass samples (Hua et al. 2004; Santos et al. 2007a; Yokoyama et al. 2010), particularly impressive is the method $\left(\mathrm{H}_{2}\right.$ reduction on Fe catalyst) reported by Santos et al. (2007a) that can graphitize and measure samples as small as $2 \mu \mathrm{g} \mathrm{C}$. Salehpour et al. (2008) reported a Zn reduction method modified from Ognibene et al. (2003) that could graphitize a few tens of micrograms of C from biological samples.

The work presented here is a continuation of the low-cost and high-throughput sealed tube $\mathrm{Zn}$ reduction method developed by Xu et al. (2007) and Khosh et al. (2010). The first paper described graphitization of samples larger than $0.1 \mathrm{mg} \mathrm{C}$ for high-precision ${ }^{14} \mathrm{C}$ AMS measurement, and the second paper demonstrated that sample sizes ranging from 15 to $100 \mu \mathrm{g}$ C could also be successfully graphitized and measured at the Keck Carbon Cycle AMS facility (KCCAMS) at the University of California, Irvine. We have recently carried out more tests in order to push the sample size limit to

${ }^{1}$ Keck Carbon Cycle AMS Laboratory, Department of Earth System Science, University of California, Irvine, California 92697-3100, USA.

${ }^{2}$ Corresponding author. Email: xxu@uci.edu.

${ }^{3}$ Department of Geography, Peking University, Beijing 100871, China.

(C) 2013 by the Arizona Board of Regents on behalf of the University of Arizona

Proceedings of the 21st International Radiocarbon Conference edited by A J T Jull \& C Hatté

RADIOCARBON, Vol 55, Nr 2-3, 2013, p 608-616 


\section{$X X u$ et al.}

$<15 \mu \mathrm{g} \mathrm{C}$ by removing the reagent $\mathrm{TiH}_{2}$, further reduction of the reactor volume, and lowering graphitization temperature. The test results, the new procedure, background, precision, and accuracy associated with the modified method will be reported and evaluated herein.

\section{METHODS}

\section{Experiments}

The reagents used in the sealed tube $\mathrm{Zn}$ reduction method by Xu et al. (2007) and Khosh et al. (2010) are $\mathrm{Zn}$ and $\mathrm{TiH}_{2}$ powders, with $\mathrm{Fe}$ as catalyst. As illustrated in Xu et al. (2007), the chemical reactions responsible for the graphite formation are both $\mathrm{H}_{2}$ and $\mathrm{Zn}$ reductions of $\mathrm{CO}_{2}$; where $\mathrm{H}_{2}$ originates when $\mathrm{TiH}_{2}$ reaches temperatures over $440{ }^{\circ} \mathrm{C}$, and $\mathrm{Zn}$ in the meantime, reduces $\mathrm{H}_{2} \mathrm{O}$ back to $\mathrm{H}_{2}$ to keep the $\mathrm{CO}_{2}$ reduction reaction going to near completion. However, a small fraction of $\mathrm{CH}_{4}$ could form in the presence of excess $\mathrm{H}_{2}$ (McNichol et al. 1992; Verkouteren et al. 1997). This is not much of a problem for regular-size samples of $1 \mathrm{mg} \mathrm{C}$ because the fraction is usually $<5 \%$ and any mass-dependent isotope fractionation associated with the incomplete graphitization can be fully corrected by the simultaneous on-line AMS $\delta^{13} \mathrm{C}$. However, $\mathrm{CH}_{4}$ formation could become a significant problem for ultra small-mass samples with $<15 \mu \mathrm{g} \mathrm{C}$. We have observed that $<10 \mu \mathrm{g} \mathrm{C}$ samples failed to graphitize following the setup by Khosh et al. (2010), although it can successfully graphitize samples of 100 to $15 \mu \mathrm{g} \mathrm{C}$ size after modifying the original method by reducing the reactor tube volume and reagents proportionally to accompany the small sample size. Graphitization can be realized without $\mathrm{H}_{2}$ or $\mathrm{TiH}_{2}$, but with $\mathrm{Zn}$ alone at a slower rate (Slota et al. 1987). We tested the method by removing $\mathrm{TiH}_{2}$ to see if it would help ultra small-mass samples reach a more complete graphitization by avoiding the formation of $\mathrm{CH}_{4}$. Since it is difficult to evaluate the graphitization yield by measuring $\mathrm{C} \%$ of such a small mass graphite, we decided to check the relative graphitization completeness (or graphite quality) by looking at its beam currents $\left({ }^{12} \mathrm{C}^{+1}\right)$ measured in the high-energy end of the AMS. Higher beam currents would indicate better or more complete graphitization assuming other conditions, such as target pressing and ion source, are more or less the same.

Figure 1 shows that when a sample size is $>15 \mu \mathrm{g} \mathrm{C}$, graphite formed with $\mathrm{TiH}_{2}$ present generally has higher currents than the ones without (Figure 1A). When a sample size is $\sim 15 \mu \mathrm{g} \mathrm{C}$ (Figure 1B), the graphite with $\mathrm{TiH}_{2}$ starts with higher currents but decreases quickly to about the same as those without $\mathrm{TiH}_{2}$ after the first 3 cycles of measurements in AMS. However, this indicates clearly that graphite formed without $\mathrm{TiH}_{2}$ present gives out much higher and more stable currents when sample size is $<15 \mu \mathrm{g} \mathrm{C}$ (Figure 1C). Based on this experimental result, $\mathrm{TiH}_{2}$ is removed for graphitization of samples $<15 \mu \mathrm{g} \mathrm{C}$ in our new ultra small-mass graphitization procedure.

\section{Procedure}

A reactor tube consists of a 6-mm-outside-diameter (OD) Pyrex ${ }^{\circledR}$ tube with Zn powder carefully placed on the bottom of the tube, and a 3.7-mm-OD glass tube, containing the Fe catalyst, resting on an indentation above the $\mathrm{Zn}$ powder. Its preparation is basically the same as described in Khosh et al. (2010) in terms of tube sizes and the amounts of $\mathrm{Zn}$ and Fe powders used, except that $\mathrm{TiH}_{2}$ is no longer needed for ultra small-mass $(<15 \mu \mathrm{g} \mathrm{C})$ graphitization (Table 1). All Pyrex tubes are prebaked at $550{ }^{\circ} \mathrm{C}$ before reagents are added, and all assembled reactor tubes are baked at $300{ }^{\circ} \mathrm{C}$ for $1 \mathrm{hr}$ before use in order to lower modern $\mathrm{C}$ contamination from ambient $\mathrm{CO}_{2}$ adsorbing to the reagents and tube surfaces (Khosh et al. 2010). The unused reactor tubes can be stored next to a dish filled with a $1 \mathrm{~N} \mathrm{NaOH}$ solution inside an airtight cabinet for about 2 weeks, and can be rebaked at $300{ }^{\circ} \mathrm{C}$ for $1 \mathrm{hr}$ if they have been stored for more than 2 weeks. 

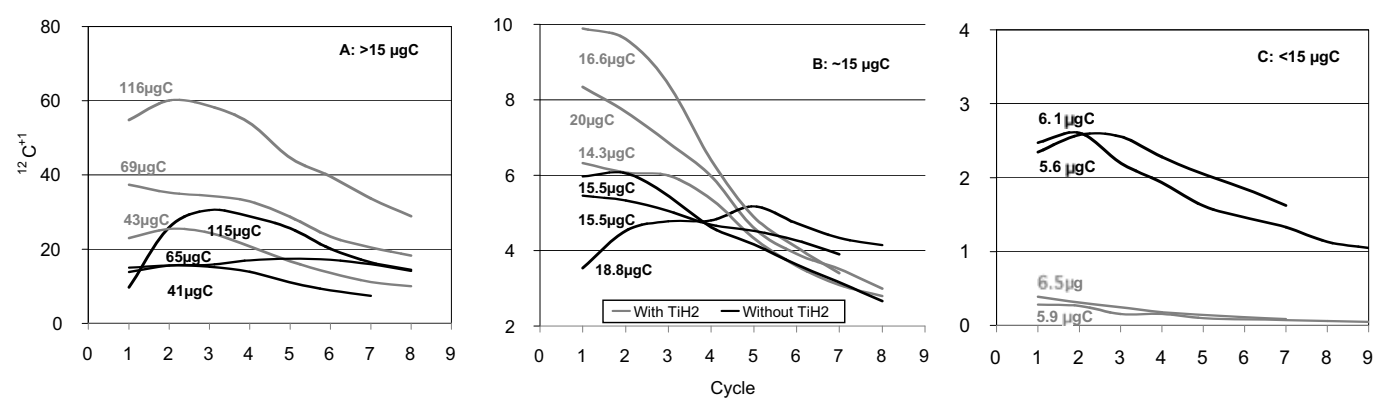

Figure 1 Beam current $\left({ }^{12} \mathrm{C}^{+1}\right.$ current at high energy) changes vs. measuring cycle on AMS for graphite samples of different sizes. Each cycle is $2.5 \mathrm{~min}$ or 50,000 counts when less than $2.5 \mathrm{~min}$. Gray lines are the graphite targets formed with the reagent $\mathrm{TiH}_{2}$ and black lines are the ones without. $\mathrm{A}, \mathrm{B}$, and $\mathrm{C}$ represent cases for sample sizes $>15, \sim 15$, and $<15 \mu \mathrm{g}$ C, respectively.

$\mathrm{CO}_{2}$ from a sample or standard combusted in a quartz tube with $\mathrm{CuO}$ is cryogenically purified on a vacuum line (see detailed descriptions in Xu et al. 2007 and Khosh et al. 2010). Extracted $\mathrm{CO}_{2}$ is quantified by a Silicon Microstructures pressure transducer (SM5812, capable of measuring 0-5 psi with a detection limit of $\sim 0.1 \mu \mathrm{g} \mathrm{C}$ ) in a known-volume reservoir. The transducer is calibrated (and recalibrated often) by several aliquots of $\mathrm{CO}_{2}$ produced by combustion of accurately weighed out known $\mathrm{C} \%$ material, such as acetanilide. After the yield is determined, $\mathrm{CO}_{2}$ is frozen into a reactor tube using liquid nitrogen and sealed off by a torch. In the method for $15-100 \mu \mathrm{g} \mathrm{C}$ samples by Khosh et al. (2010), the reactor tube was sealed off to a length of $\sim 100 \mathrm{~mm}$, or a volume of $1.3 \mathrm{~cm}^{3}$. In the modified method, the reactor tube is sealed off shorter, to $\sim 60 \mathrm{~mm}$ long, or a volume of $\sim 0.75 \mathrm{~cm}^{3}$.

Sealed reactor tubes are set upright in an aluminum block and placed inside a muffle furnace to graphitize at $450{ }^{\circ} \mathrm{C}$ for $7 \mathrm{hr}$. The temperature is reduced from the regular-size sample graphitization settings of $500{ }^{\circ} \mathrm{C}$ for $3 \mathrm{hr}$ plus $550^{\circ} \mathrm{C}$ for $4 \mathrm{hr}$. This follows the graphitization temperature setting for ultra small-mass samples reported by Santos et al. (2007a) where they showed that lower temperature helped to increase graphitization yields.

Table 1 Dimensions of reaction tubes used for the graphitization of ultra small-mass (5-15 $\mu \mathrm{g} \mathrm{C})$ samples. Numbers in parentheses are tube sizes after sealing. Amounts of zinc (Aldrich, \#324930) and iron catalyst (400-mesh, Sigma-Aldrich, \#05406) used in the graphitization process are listed in the last 2 columns. The reagent zinc is placed in the bottom of the outer tube and catalyst iron is placed in small borosilicate tube that sits inside on a dimple made $\sim 1 \mathrm{~cm}$ from the base of the reaction tube.

\begin{tabular}{lllllll}
\hline & OD $(\mathrm{mm})$ & $\mathrm{ID}(\mathrm{mm})$ & Height $(\mathrm{mm})$ & Volume $\left(\mathrm{cm}^{3}\right)$ & $\mathrm{Zn}(\mathrm{mg})$ & $\mathrm{Fe}(\mathrm{mg})$ \\
\hline Outer tube & 6 & 4 & $152(60)$ & $1.91(0.75)$ & $9.8-11.4$ & \\
Inside tube & 3.7 & 3 & 25 & 0.18 & & $4-5$ \\
\hline
\end{tabular}

\section{Performance of Graphite in Ion Source}

High ionization efficiency in the ion source followed by high beam currents after the accelerator is a prerequisite for getting high-performance measurements on ultra-small samples. The AMS system at KCCAMS where our ultra small-mass graphite samples are measured is a NEC $0.5 \mathrm{MV} 1.5 \mathrm{SDH}-$ 1 machine that uses a modified NEC MC-SNIC ion source (Southon and Santos 2007). It is capable of generating high beam currents of $\sim 80-100 \mu \mathrm{A}{ }^{12} \mathrm{C}^{+1}$ for regular-size samples of $\sim 1 \mathrm{mg} \mathrm{C}$, and 


\section{$X X u$ et al.}

about $1 \mu \mathrm{A} / 1 \mu \mathrm{g} \mathrm{C}$ for samples ranging between $2-10 \mu \mathrm{g} \mathrm{C}$ for graphite produced by the $\mathrm{H}_{2}$ reduction method (Santos et al. 2007a). As expected, currents produced by ultra small-mass samples are strongly mass dependent. Maximum ${ }^{12} \mathrm{C}^{+1}$ currents of $\sim 0.5 \mu \mathrm{A} / 1 \mu \mathrm{g} \mathrm{C}$ were obtained for $5-15 \mu \mathrm{g} \mathrm{C}$ samples prepared with this method (Figure 2), which is similar to the current $(\mu \mathrm{A}) / \operatorname{size}(\mu \mathrm{g} \mathrm{C})$ observed for 15-100 $\mu \mathrm{g} \mathrm{C}$ samples reported by Khosh et al. (2010). The lower beam current per sample size compared to that of the $\mathrm{H}_{2}$ reduction method may be resulting from a lower graphitization yield by the sealed tube $\mathrm{Zn}$ reduction method.

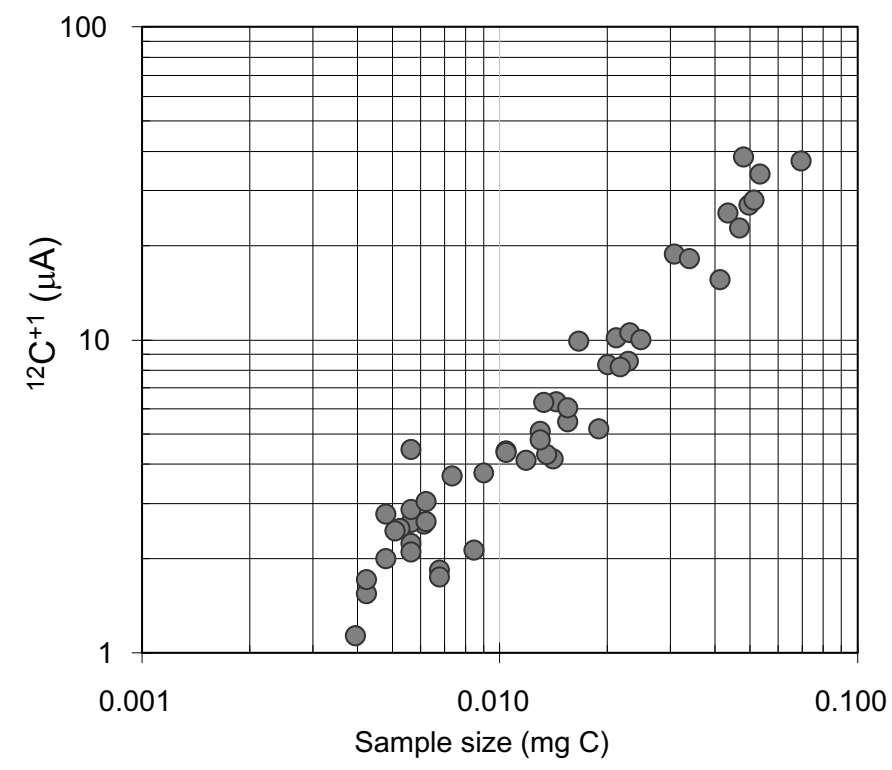

Figure 2 Plot of the maximum ${ }^{12} \mathrm{C}^{+1}$ beam current versus sample size

\section{Mass-Dependent C Isotope Fractionation Correction}

Proper on-line AMS $\delta^{13} \mathrm{C}$ measurement is another prerequisite for getting reasonably good precision and accuracy for ${ }^{14} \mathrm{C}$ measurements on small and ultra small-mass samples. Regardless of sample size, all AMS ${ }^{14} \mathrm{C}$ measurements made at KCCAMS are currently corrected using AMS $\delta^{13} \mathrm{C}$ values. For ultra-small samples, this is more critical because they tend to fractionate much more than regular-size samples inside the machine. A drift of as much as $20 \%$ from that of the original material has been observed based on the AMS $\delta^{13} \mathrm{C}$ measurements (Santos et al. 2007a). Also, the ranges and patterns of AMS $\delta^{13} \mathrm{C}$ drifting with sample size and running time can be highly variable from target to target, and from wheel to wheel. In addition, mass-dependent fractionation also occurs during the graphitization process when using the sealed tube $\mathrm{Zn}$ reduction method, as described by $\mathrm{Xu}$ et al. (2007). Therefore, simultaneous on-line AMS $\delta^{13} \mathrm{C}$ measurement that allows for correction of both isotopic fractionation processes during graphitization and inside the AMS machine is a key step in the measurement.

\section{RESULTS AND DISCUSSION}

\section{Background}

For background corrections and normalizing AMS ${ }^{14} \mathrm{C}$ measurements of small to ultra small-mass samples, we adopt the standard and blank setup in a wheel from the non-matching method described 
by Santos et al. (2007a). In this method, the modern $C$ background is estimated and corrected based on a set of ${ }^{14} \mathrm{C}$-free material, such as coal, covering the size range of the ultra-small samples, and the dead-C background is corrected based on a set of similar-sized modern standard, such as OX-I (Khosh et al. 2010). Results from our test wheels show that the modern $\mathrm{C}$ background is $\sim 0.2-0.8$ $\mu \mathrm{g} \mathrm{C}$ (Figure 3) and dead-C background is $\sim 0.1-0.4 \mu \mathrm{g} \mathrm{C}$. Accurate $\mathrm{CO}_{2}$ size quantification is important since all background corrections are size dependent.

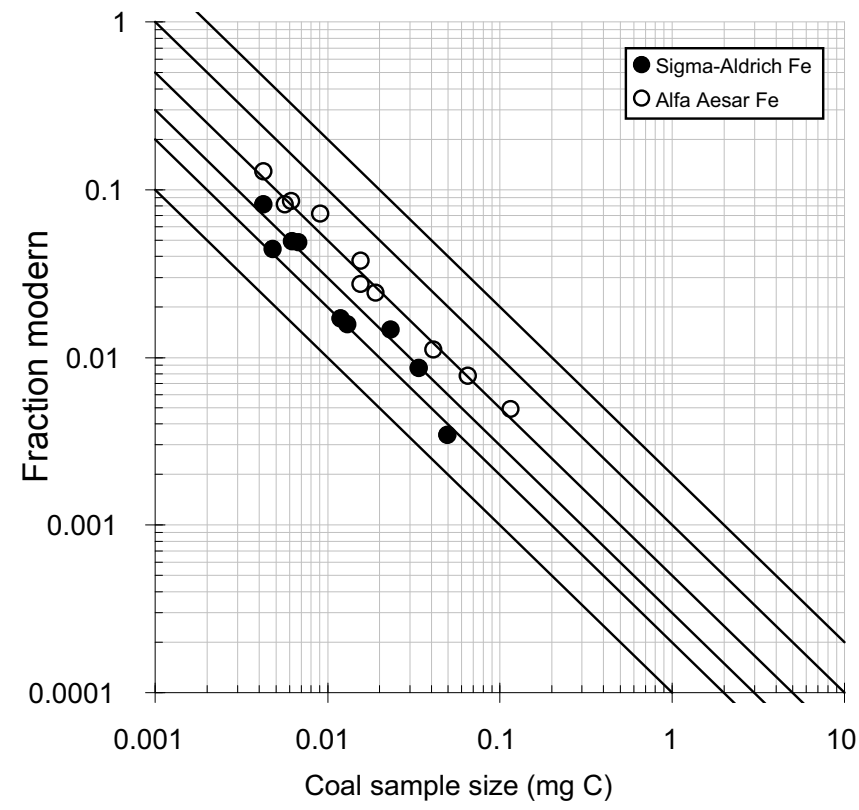

Figure 3 Modern $\mathrm{C}$ background estimates. 400-mesh Fe powder from Sigma-Aldrich (solid circles) has yielded further improved backgrounds over 325-mesh Fe powder from Alfa Aesar (open circles) used previously. Solid lines represent $0.1,0.2,0.3,0.5,1.0$, and $2.0 \mu \mathrm{g}$ of modern $\mathrm{C}$ contamination.

Reducing the modern $\mathrm{C}$ background component remains a challenge to make this method useful for older samples. Baking assembled reaction tubes at $300^{\circ} \mathrm{C}$ for $1 \mathrm{hr}$ before use was found to produce the best results by Khosh et al. (2010). We have kept this cleaning procedure for our ultra smallmass samples, and we prefer to do the baking right before graphitization to minimize ambient $\mathrm{CO}_{2}$ adsorption onto the surfaces of reagents and the glass tube walls. We have also examined the modern $\mathrm{C}$ backgrounds of the 400-mesh Fe powder from Sigma-Aldrich. The test results show that the finer Fe catalyst from Sigma-Aldrich indeed has lower modern C blank than the Alfa Aesar 325-mesh Fe that is used for our regular-size sample graphitization (Figure 3), and this is consistent with what Santos et al. (2007b) reported. However, Sigma-Aldrich 400-mesh Fe was found to have a tendency to sinter during $\mathrm{H}_{2}$-reduced graphitization, and thus is not used with our regular-size samples. On the other hand, ultra small-mass graphite produced by sealed tube $\mathrm{Zn}$ reduction appears to be more chunky and harder than regular-sized $\mathrm{Zn}$-reduced graphite. The chunky characteristics of smallsample graphite is the result of not enough $\mathrm{CO}_{2}$ to form fluffy filamentous graphite, and instead small patches of $\mathrm{Fe}_{3} \mathrm{C}$ are formed. This is illustrated in a scanning electron microscope (SEM) image of a small-sample graphite with $0.011 \mathrm{mg} \mathrm{C}$, reported by Santos et al. (2007c, Figure 5). The use of Sigma-Aldrich 400-mesh Fe in this study does not seem to have made the ultra small-mass graphite harder to press into the target holders. The less sintering may be due to the fact that graphitizing tem- 


\section{$X X u$ et al.}

perature is reduced from 550 to $450{ }^{\circ} \mathrm{C}$ in this modified method. Therefore, Sigma-Aldrich $400-$ mesh Fe has been substituted for the Alfa Aesar 325-mesh Fe in our ultra small-mass sample graphitization procedure.

It should be noted that the backgrounds discussed here only include those from combustion, graphitization, target press, and machine-induced. Backgrounds associated with prior sample processes, such as chemical and physical separations, are not discussed here, but they can be much higher and should be investigated carefully and accounted for properly in background corrections and in the final error calculations.

\section{Precision and Accuracy}

To test the accuracy and precision of this modified method, ultra small-mass samples of primary and secondary standards (OX-I, OX-II, ANU sucrose, and TIRI Wood B) spanning a 5-15 $\mu \mathrm{g} \mathrm{C}$ range were measured and normalized to regular-size $(1 \mathrm{mg} \mathrm{C})$ OX-I standards using the non-matching method described by Santos et al. (2007a). Figure 4 shows the results of the 4 small-mass standards after all corrections have been applied. Final results of all 4 small-mass samples are consistent with the corresponding sample consensus values, indicating that both modern-carbon and dead-C backgrounds for this method are correctable.
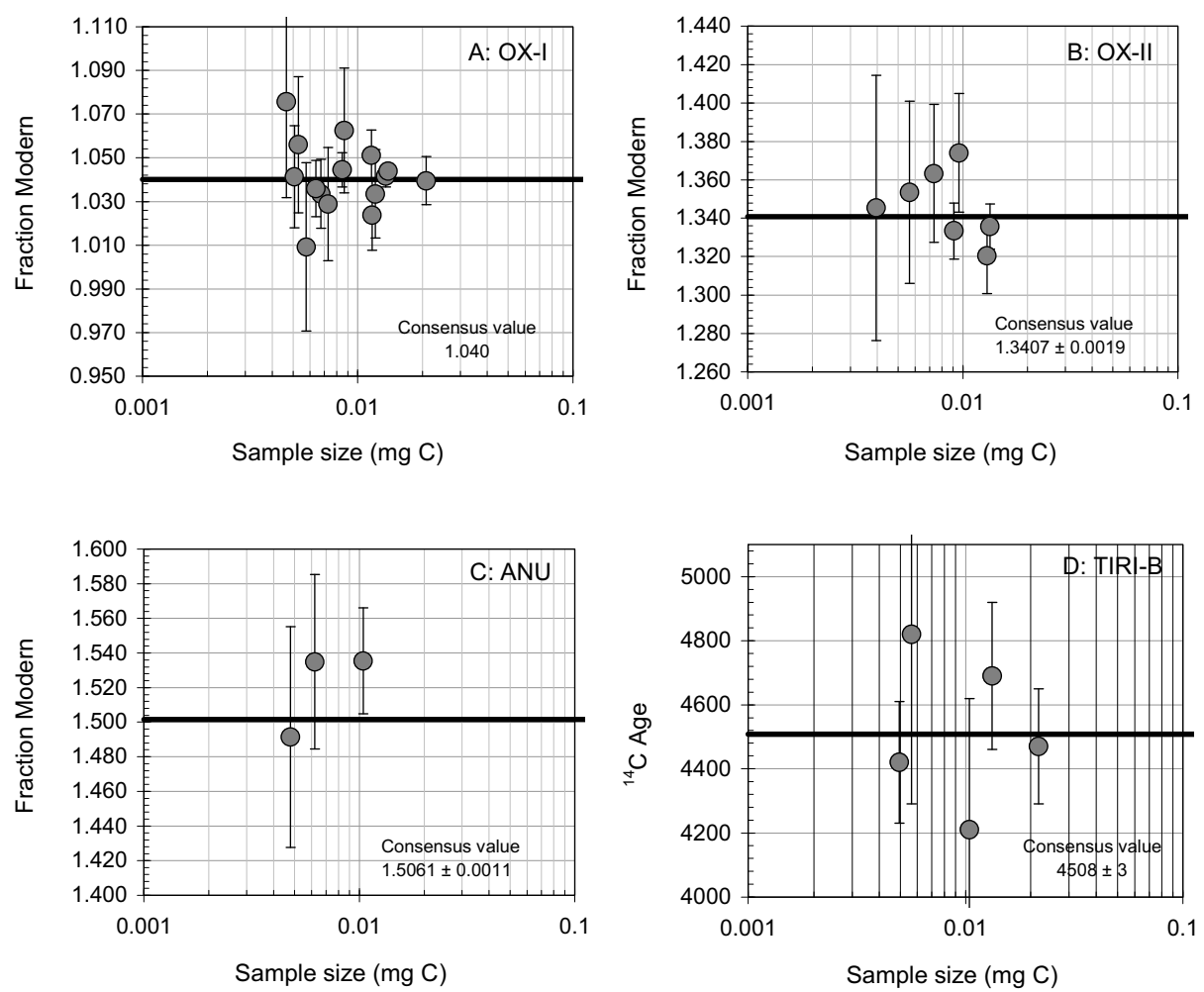

Figure 4 Fraction modern results for OX-I (A), OX-II (B), and ANU (C) samples, and ${ }^{14} \mathrm{C}$ age results for TIRI-B (D) samples ranging from $0.005-0.020 \mathrm{mg} C$, measured from multiple wheels by AMS at KCCAMS. Solid lines represent the consensus values of the standards. Error bars are $\pm 1 \sigma$. Results have been normalized to independent sets of six 1-mg C OX-I standards in each wheel. All results have been corrected for both machine- and graphitization-induced isotopic fractionation using the simultaneous on-line $\mathrm{AMS} \delta^{13} \mathrm{C}$ measurements. 
The accuracy and precision of ultra small-mass samples prepared by this method are size and ${ }^{14} \mathrm{C}$ content dependent, but is usually $\pm 4-5 \%$ for modern samples of size $\sim 4-5 \mu \mathrm{g} \mathrm{C}$, based on the limited number of duplicate measurements of primary and secondary standards. The analytical errors (see error bars in Figure 4) heavily depend on the sizes and uncertainties of both the modern and dead-C components.

\section{An Example of Ultra Small-Mass ${ }^{14} \mathrm{C}$ Measurement}

Quartz filter blank evaluation is important, although difficult, for particulate organic carbon (POC) ${ }^{14} \mathrm{C}$ measurements since quartz filters are often combusted together with the POC collected on them. Researchers have noticed that the magnitude and variability of the extraneous $\mathrm{C}$ found in processed quartz filters subjected to similar POC collection and handling procedures can be large. As a result, the filter blank has become one the biggest obstacles in preventing high-precision measurements of POC ${ }^{14} \mathrm{C}$ AMS, when the amount of expected POC is small, such as in ice cores (Steier et al. 2006).

We examined the size and effect of storage time on Whatman quartz filter blanks $(2.2 \mu \mathrm{m}$ pore size, $32 \mathrm{~mm}$ diameter). Filters were precleaned by baking at either $500{ }^{\circ} \mathrm{C}$ or $900{ }^{\circ} \mathrm{C}$ for $2 \mathrm{hr}$. (No difference was found between these 2 baking temperatures in terms of size of the blank.) Filters were stored for different amounts of time: 0,7 , or 30 days. Then, 2 prebaked filters were loaded in a prebaked 9-mm-OD quartz tube with $\mathrm{CuO}$, evacuated, sealed, and combusted at $900{ }^{\circ} \mathrm{C}$ for $3 \mathrm{hr}$. $\mathrm{CO}_{2}$ was cryogenically purified and graphitized if the amount was $>4 \mu \mathrm{g} \mathrm{C}$, using this sealed tube ultra small-sample method.

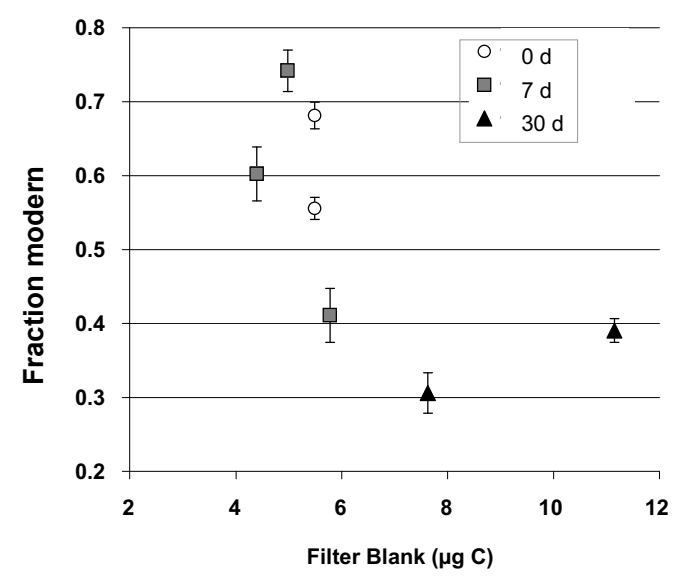

Figure 5 Plot of FM of Whatman quartz filters vs. filter blank size $(\mu \mathrm{g} \mathrm{C})$ at different lengths of storage time ranging from 0 day (open circles), 7 days (gray squares), and 30 days (black triangles).

Figure 5 shows that there is no significant difference in quartz filter blank size between 0 and 7 days of storage time. The filter blank ranges from 4.4 to $5.8 \mu \mathrm{g} \mathrm{C}$ for two 32-mm-diameter Whatman filters, or $0.18-0.24 \mu \mathrm{g} \mathrm{C} / \mathrm{cm}^{2}$ of filter area. Despite the relatively constant blank size, the variation of ${ }^{14} \mathrm{C}$ content of the blank is surprisingly large, from 0.41 to $0.74 \mathrm{Fm}$. Although we do not know why the ${ }^{14} \mathrm{C}$ range is so big, the sources of the filter blank seem to be from a mixture of modern $\mathrm{CO}_{2}$ and old volatile organic $\mathrm{C}$ (VOC) in the lab ambient air. Blank size increased to 7.6-11.1 $\mu \mathrm{g} \mathrm{C}$ (or 0.32$0.46 \mu \mathrm{g} \mathrm{C} / \mathrm{cm}^{2}$ ) after 30 days of storage in prebaked glass jars. In the meantime, ${ }^{14} \mathrm{C}$ of the blank 


\section{$X X u$ et al.}

decreased to $0.31-0.39 \mathrm{Fm}$, which may indicate a higher fraction of VOC adsorption onto the filters with longer storage time. These results show that the much higher processed filter blanks observed before (as high as $17 \mu \mathrm{g} \mathrm{C} / \mathrm{cm}^{2}$, Steier et al. 2006; $6 \mu \mathrm{g} \mathrm{C} / \mathrm{cm}^{2}$, personal communication with Fenwei Zeng) probably did not come from the filter itself or due to prebaking or regular storage in air (if $<30$ days), but most likely due to processes during sample collection and handling. In addition, the large variation in filter blank ${ }^{14} \mathrm{C}$ would make the filter blank correction on $\mathrm{POC}{ }^{14} \mathrm{C}$ measurements more challenging. Nevertheless, the results have proven that the modified sealed tube $\mathrm{Zn}$ reduction method can be successfully applied to ultra-small samples, such as to evaluate quartz filter blanks.

\section{CONCLUSIONS}

Removing the reagent $\mathrm{TiH}_{2}$, reducing the sealed reactor volume to $\sim 0.75 \mathrm{~cm}^{3}$, and lowering the graphitization temperature to $450{ }^{\circ} \mathrm{C}$ have helped to successfully extend the sample size range to $4-$ $15 \mu \mathrm{g} \mathrm{C}$ using the sealed tube $\mathrm{Zn}$ reduction graphitization method developed by Xu et al. (2007) and modified by Khosh et al. (2010) when measured on the AMS system at KCCAMS. Table 2 summarizes the differences and improvements of the sealed tube graphitization method from 2007 and 2010 to current work. Both modern and dead-C backgrounds from combustion and graphitization are compatible to those from the ultra small-mass $\mathrm{H}_{2}$ reduction method by Santos et al. (2007a). Although the $\mathrm{H}_{2}$ reduction method can graphitize smaller sample sizes $(2 \mu \mathrm{g} \mathrm{C})$, the low cost, high throughput, and ease in storage of graphite after formation still make this method useful for many applications where the ${ }^{14} \mathrm{C}$ content variation is large in samples and thus do not require ultra high precision. Also, we should bear in mind that in many cases backgrounds associated with sample pretreatments, such as those in specific compound separations, are often much larger than the backgrounds from combustion/graphitization and thus become the limiting factors in determining the usefulness of ultra small-sample ${ }^{14} \mathrm{C}$ data rather than the graphitization process itself (Santos et al. 2010).

Table 2 Differences and improvements of sealed tube $\mathrm{Zn}$ reduction graphitization method from 2007 and 2010 to current work.

\begin{tabular}{|c|c|c|c|c|}
\hline Paper & $\begin{array}{l}\text { Sample size } \\
(\mathrm{mg} \mathrm{C})\end{array}$ & $\begin{array}{l}\text { Reaction tube } \\
\text { (outer/inside) }\end{array}$ & Reagents & $\begin{array}{l}\text { Modern } \mathrm{C} \text { back- } \\
\text { ground }\left({ }^{14} \mathrm{C} \mathrm{yr}\right)\end{array}$ \\
\hline Xu et al. (2007) & $0.1-1.2$ & $9 \mathrm{~mm} \mathrm{OD} / 6 \mathrm{~mm} \mathrm{OD}$ & $\mathrm{Zn}, \mathrm{TiH}_{2}$, and $\mathrm{Fe}$ & $\sim 50,000$ for $1 \mathrm{mg} \mathrm{C}$ \\
\hline Khosh et al. (2010) & $0.015-0.1$ & $6 \mathrm{~mm} \mathrm{OD} / 3.7 \mathrm{~mm} \mathrm{OD}$ & $\begin{array}{l}\text { Downsized } \mathrm{Zn} \text { and } \mathrm{TiH}_{2} \\
\text { with same amount of } \mathrm{Fe}\end{array}$ & $\begin{array}{l}\text { Up to } 58,000 \text { for } 1 \mathrm{mg} \\
\mathrm{C} \text {; Modern } \mathrm{C} \text { as low } \\
\text { as } 0.3 \mu \mathrm{g} \mathrm{C}\end{array}$ \\
\hline This work & $0.004-0.015$ & $\begin{array}{l}\text { Shorter } 6 \mathrm{~mm} \text { OD/ } \\
3.7 \mathrm{~mm} \mathrm{OD}\end{array}$ & $\begin{array}{l}\text { Downsized } \mathrm{Zn} \text {, no } \mathrm{TiH}_{2} \text {, } \\
\text { same amount of } \mathrm{Fe}\end{array}$ & $\begin{array}{l}\text { Modern } \mathrm{C} \text { as low as } \\
0.2 \mu \mathrm{g} \mathrm{C}\end{array}$ \\
\hline
\end{tabular}

\section{ACKNOWLEDGMENTS}

The authors would like to thank the WM Keck foundation and UCI for their financial support. We are very thankful for the help and support in the development of this method provided to us by Guaciara Santos and John Southon. We also gratefully acknowledge the help provided by Aubrey Stills and Mariela Ruacho in the lab.

\section{REFERENCES}

Fahrni SM, Gäggeler HW, Hajdas I, Ruff IM, Szidat S, Wacker L. 2010. Direct measurements of small ${ }^{14} \mathrm{C}$ samples after oxidation in quartz tubes. Nuclear Instruments and Methods in Physics Research B 268(78):787-9.
Hua Q, Zoppi U, Williams AA, Smith AM. 2004. Smallmass AMS radiocarbon analysis at ANTARES. $\mathrm{Nu}$ clear Instruments and Methods in Physics Research B 223-224:284-92.

Khosh MS, Xu X, Trumbore SE. 2010. Small-mass 


\section{Ultra Small-Mass Graphitization by Sealed Tube Zinc Reduction}

graphite preparation by sealed tube zinc reduction method for AMS ${ }^{14} \mathrm{C}$ measurements. Nuclear Instruments and Methods in Physics Research B 268(7-8): 927-30.

McNichol AP, Gagnon AR, Jones GA, Osborne EA. 1992. Illumination of a black box: analysis of gas composition during graphite target preparation. $R a-$ diocarbon 34(3):321-9.

Ognibene TJ, Bench G, Vogel JS. 2003. A high-throughput method for the conversion of $\mathrm{CO}_{2}$ obtained from biochemical samples to graphite in septa-sealed vials for quantification of ${ }^{14} \mathrm{C}$ via accelerator mass spectrometry. Analytical Chemistry 75(9):2192-6.

Salehpour M, Possnert G, Bryhni H. 2008. Subattomole sensitivity in biological accelerator mass spectrometry. Analytical Chemistry 80(10):3515-21.

Santos GM, Southon JR, Griffin S, Beaupre SR, Druffel ERM. 2007a. Ultra small-mass AMS ${ }^{14} \mathrm{C}$ sample preparation and analyses at KCCAMS/UCI Facility. $\mathrm{Nu}$ clear Instruments and Methods in Physics Research $B$ 259(1):293-302.

Santos GM, Mazon M, Southon JR, Rifai S, Moore R. 2007b. Evaluation of iron and cobalt powders as catalysts for ${ }^{14} \mathrm{C}$-AMS target preparation. Nuclear Instruments and Methods in Physics Research B 259(1): 308-15.

Santos GM, Moore RB, Southon JR, Griffin S, Hinger E, Zhang D. 2007c. AMS ${ }^{14} \mathrm{C}$ sample preparation at the KCCAMS/UCI Facility: status report and performance of small samples. Radiocarbon 52(2):255-69.

Santos GM, Southon JR, Drenzek NJ, Ziolkowski LA, Druffel ERM, Xu X, Zhang D, Trumbore SE, Eglinton TI, Hughen KA. 2010. Blank assessment for ultra- small radiocarbon samples: chemical extraction and separation versus AMS. Radiocarbon 52(3):1322-35.

Slota Jr PJ, Jull AJT, Linick TW, Toolin LJ. 1987. Preparation of small samples for ${ }^{14} \mathrm{C}$ accelerator targets by catalytic reduction of CO. Radiocarbon 29(2):303-6.

Southon JR, Santos GM. 2004. Ion source development at KCCAMS, University of California, Irvine. Radiocarbon 46(1):33-9.

Southon JR, Santos GM. 2007. Life with MC-SNICS. Part II: Further ion source development at the Keck carbon cycle AMS facility. Nuclear Instruments and Methods in Physics Research B 259(1):88-93.

Steier P, Shah SR, Drosg R, Pearson A, Fedi M, Kutschera W, Schock M, Wagenbach D, Wild EM. 2006. Radiocarbon determination of particulate organic carbon in non-temperated, Alpine glacier ice. Radiocarbon 48(1):69-82.

Verkouteren RM, Klinedinst DB, Currie LA. 1997. Ironmanganese system for preparation of radiocarbon AMS targets: characterization of procedural chemical-isotopic blanks and fractionation. Radiocarbon 39(3):269-83.

Xu X, Trumbore SE, Zheng S, Southon JR, McDuffee KE, Luttgen M, Liu JC. 2007. Modifying a sealed tube zinc reduction method for preparation of AMS graphite targets: reducing background and attaining high precision. Nuclear Instruments and Methods in Physics Research B 259(1):320-9.

Yokoyama Y, Koizumi M, Matsuzaki H, Miyairi Y, Ohkouchi N. 2010. Developing ultra small-scale radiocarbon sample measurement at the University of Tokyo. Radiocarbon 52(2):310-8. 